\title{
The impact of transmural multiprofessional simulation-based obstetric team training on perinatal outcome and quality of care in the Netherlands
}

Franyke R Banga ${ }^{1 *}$, Sophie E M Truijens ${ }^{1}$, Annemarie F Fransen ${ }^{1}$, Jeanne P Dieleman²,

Pieter J van Runnard Heimel ${ }^{1}$ and Guid S Oei ${ }^{1,3}$

\begin{abstract}
Background: Perinatal mortality and morbidity in the Netherlands is relatively high compared to other European countries. Our country has a unique system with an independent primary care providing care to low-risk pregnancies and a secondary/tertiary care responsible for high-risk pregnancies. About $65 \%$ of pregnant women in the Netherlands will be referred from primary to secondary care implicating multiple medical handovers. Dutch audits concluded that in the entire obstetric collaborative network process parameters could be improved. Studies have shown that obstetric team training improves perinatal outcome and that simulation-based obstetric team training implementing crew resource management (CRM) improves team performance. In addition, deliberate practice (DP) improves medical skills. The aim of this study is to analyse whether transmural multiprofessional simulation-based obstetric team training improves perinatal outcome.

Methods/Design: The study will be implemented in the south-eastern part of the Netherlands with an annual delivery rate of over 9,000. In this area secondary care is provided by four hospitals. Each hospital with referring primary care practices will form a cluster (study group). Within each cluster, teams will be formed of different care providers representing the obstetric collaborative network. CRM and elements of DP will be implemented in the training. To analyse the quality of care as perceived by patients, the Pregnancy and Childbirth Questionnaire (PCQ) will be used. Furthermore, self-reported collaboration between care providers will be assessed. Team performance will be measured by the Clinical Teamwork Scale (CTS). We employ a stepped-wedge trial design with a sequential roll-out of the trainings for the different study groups.

Primary outcome will be perinatal mortality and/or admission to a NICU. Secondary outcome will be team performance, quality of care as perceived by patients, and collaboration among care providers.
\end{abstract}

Conclusion: The effect of transmural multiprofessional simulation-based obstetric team training on perinatal outcome has never been studied. We hypothesise that this training will improve perinatal outcome, team performance, and quality of care as perceived by patients and care providers.

Trial registration: The Netherlands National Trial Register, www.trialregister.nI/NTR4576, registered June 1, 2014

Keywords: Multiprofessional, Simulation-based obstetric team training, Deliberate practice, Crew resource management, Quality of care

\footnotetext{
* Correspondence: f.banga@mmc.nl

'Department of Obstetrics and Gynaecology, Máxima Medical Centre, De Run 4600, P.O. Box 7777, 5500 MB Veldhoven, The Netherlands

Full list of author information is available at the end of the article
} 


\section{Background}

\section{Perinatal mortality in the Netherlands}

Perinatal mortality and morbidity in the Netherlands is relatively high compared to other countries in Europe, shown by Peristat I (data of 1999) [1] and Peristat II (data of 2004) [2-4]. Initiated by the Dutch Minister of Health, a Committee Project group Pregnancy and Birth was started in 2008, just after publication of Peristat II. The main goal was to improve quality of obstetric care in the Netherlands. Beside several implementations such as regional Obstetric Cooperatives and the Dutch Perinatal Audit, a nation-wide research programme on pregnancy and birth of the Netherlands Organization for Health, Research and Development (ZonMw) was developed. Recently, the data of the third Euro-Perinatal European Perinatal Health Report (data of 2010) were launched [5]. Perinatal mortality in the Netherlands has declined with $14 \%$ between 2004 and 2010, however the current mortality rate still represents a poor international position, which is even more remarkable considering that the Netherlands was ranked second highest in Europe concerning welfare [6]. In 2004, the Netherlands featured the third highest perinatal mortality (out of 26 countries). In 2010, the Netherlands ranked the sixth highest perinatal mortality out of 29 European countries. The perinatal mortality in the Netherlands should decrease faster than in other European countries in order to be ranked in the top.

\section{Dutch system}

The Netherlands has an estimated population of 16.7 million. In the Netherlands, around 175,000 children are born yearly, of which around 1,500 babies die (perinatal mortality). Obstetric care is organised in low-risk primary care, medium-risk secondary, and high-risk tertiary care (Figure 1). Primary care concerning low-risk pregnancies is represented by independent midwives (and general practitioners). A low-risk pregnant woman has the possibility of planning her delivery either at home or in a primary care hospital setting, both under responsibility of her own independent midwife. The Netherlands has a high rate of home delivery, although rate is declining from $26 \%$ home deliveries in 2007 to $15.6 \%$ in 2012 [7]. Secondary care is regionally organised in 92 hospitals of which 10 hospitals provide tertiary care in a perinatology centre facilitating a Neonatal Intensive Care Unit (NICU) and an Obstetric High Care unit (OHC). Secondary and tertiary care is provided by obstetric nurses, secondary care (hospital) midwives, residents and obstetricians, working together in teams. During pregnancy and/or delivery a pregnant woman may evolve from low-risk to medium- or high-risk, followed by a referral from primary to secondary or tertiary care. Indications for referral are defined in the 'Obstetric Indication List' [8]. Perinatal data of 2007 show a huge shift between primary and secondary/tertiary care: the intention (42\%) and reality (26\%) to deliver at home, the intention (42\%) and reality (16\%) to deliver in primary care in hospital, and the intention (16\%) and reality (61\%) to deliver in secondary care in hospital [9-14]. This shift between primary and secondary care is getting more extensive when interpreting recent perinatal data of 2012: about $85 \%$ of pregnancies starts in primary care and $15 \%$ in secondary/tertiary care. Finally, 30\% will give birth in primary care and $70 \%$ in secondary/tertiary care. This means that about $65 \%$ of all pregnancies will be referred from primary to secondary/ tertiary care, during pregnancy or delivery [7]. This extensive shift between the different care levels results in multiple medical handovers, potentially causing errors in communication and process management.

\section{Risk of home delivery}

A recent Dutch study showed a higher risk of delivery related perinatal mortality among women with planned delivery in primary care (at home or in hospital) compared

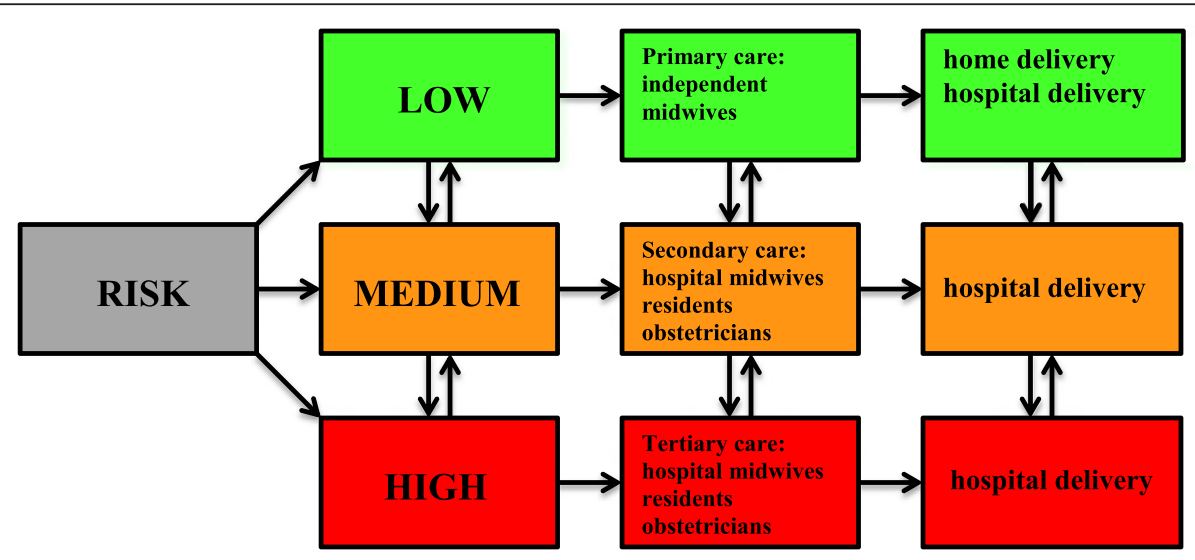

Figure 1 Obstetric system in the Netherlands: based on risk selection organised in independent primary, secondary and tertiary care. The arrows reflect possible referrals during pregnancy and delivery. 
to women who started delivery in secondary care. An even higher risk of perinatal mortality was found in women who were referred from primary to secondary care during delivery [15]. Another Dutch study did not find a significant difference between a planned home and hospital delivery among low-risk women in primary care [16]. However, the results of these two Dutch studies cannot be compared because different groups and different comparisons were studied: the first study compared planned primary care delivery with planned secondary care delivery while the second study compared planned home delivery with planned hospital delivery in primary care. The British Birthplace cohort study concluded that nulliparous low risk women with a planned home delivery have an increased incidence of adverse perinatal outcome. For multiparous women, there were no significant differences in adverse perinatal outcome by planned place of birth. Interventions during delivery were substantially lower in all non-obstetric unit settings [17].

\section{Causes of perinatal death}

Analysis of Dutch data showed that $85.2 \%$ of perinatal mortality is caused by one or more of the four following disorders, together the so called Big 4: small for gestational age (SGA: birth weight below $10^{\text {th }}$ percentile), preterm delivery before 37 weeks of gestation, congenital anomaly and low Apgar score (Apgar score below 7). Big 4 disorders are overlapping each other often, creating a multiple diagnosis. Accumulation of Big 4 disorders obviously increases mortality rate. The group with exclusively one Big 4 disorder causing perinatal death is small. Of all pregnancies, 16.3\% represents a Big 4 disorder. Of all Big 4 pregnancies, $29 \%$ starts delivery in primary care. This indicates that risk selection is inadequate. $[9,18-20]$. These data suggest that evaluation and improvement of process management of pregnancies complicated by a Big 4 disorder will be beneficial for perinatal outcome.

\section{Process parameters and communication audit}

Analysis of all term perinatal death cases in 2010 by the Dutch Perinatal Audit revealed one or more substandard factors (SSF) in $52 \%$ of the cases. In $56 \%$ of the cases with SSF, multiple care providers were involved. In $44 \%$ of the cases with SSF there was a possible or (very) probable relation with perinatal death. International research described a possible or (very) probable relation with perinatal death in 25-30\% of all perinatal death cases with substandard care [21]. The Dutch Perinatal Audit has recommended the following: develop uniform care paths, focus on standardised communication and handovers based on the SBAR system (Situation, Background, Assessment, Recommendation), and organise team trainings [22]. It has become clear that within the entire obstetric collaborative network process parameters can be improved.
Communication between obstetric care providers within one discipline as well as between different disciplines is important to guarantee an optimal referral process. Moreover, adequate and uniform communication towards the patient (and partner) is important for positive perception $[9,18,22]$.

\section{Quality of care as perceived by patients}

During the last decade, there has been growing interest in quality of care as perceived by patients. With increasing attention to patient-centered care, indicators of care quality more and more involve perceived quality of care and patient satisfaction [23-26]. Measuring patient-reported outcomes is a common strategy used to monitor quality of care in a number of countries. Because of the unique obstetric care system in the Netherlands with different care levels, pregnant women often see different care providers [27]. Recently published data showed that patients who had been referred from primary to secondary care report lower quality of care [28]. These patients received care in more than one institution, from several care providers. Referral during pregnancy and delivery may have a negative effect on a systematic way of communication towards the patients and might cause inconsistency in advice, information, and protocols [28].

\section{Simulation-based team training}

Team training in obstetric emergencies reduces poor perinatal outcome as was shown by a British retrospective cohort study [29]. Recently, a systematic review has concluded that medical simulation is effective for medical education [30]. A meta-analysis showed that simulationbased medical education (SBME) with deliberate practice (DP) is superior in improving medical skills to traditional clinical medical education such as the Halstedian approach (see one, do one, teach one) [31]. DP reflects a life-long period of deliberate effort to improve performance in a specific domain. There are nine elements of DP: 1 ) high motivation and concentration, 2) well-defined learning objects, 3) appropriate level of difficulty, 4) focused, repetitive practice, 5) rigorous, reliable measurements, 6) feedback, 7) monitoring, error correction, 8) evaluation and performance that may reach a master standard, 9) advancement to the next task [32]. Crew resource management (CRM) has been defined as 'error management capability to detect, avoid, trap or mitigate the effects of human error and therefore prevent fatal accidents'. It was developed primarily for improving air safety [33]. CRM is a training system that focuses on interpersonal communication, leadership and decision-making. It focuses on the ability of each team member to see, analyse and react, and thereby reducing potential errors. It pursues an open culture where the freedom to respectfully question authority is encouraged. Learning goals of CRM are: enhanced situational awareness, self-awareness, leadership, 
assertiveness, decision-making, flexibility, adaptability and communication. CRM in team training has shown to improve those competences and results in a positive attitude of trainees towards team building and communication [34]. A positive attitude of trainees, as represented by the first level of Kirkpatrick's model for evaluation of a training, should result in a learning effect (Kirkpatrick level two) and behavioural change (level three) and finally be translated in patient outcomes (level four) (Figure 2) [35]. A recent study concluded that simulation-based obstetric team training using the concepts of CRM results in a significant improvement in team performance and application of essential medical skills [36]. In our study, multiprofessional teams will be trained in a medical simulation centre with simulated settings that resemble reality as closely as possible. Commercially available high fidelity patient simulators (Noelle ${ }^{\mathrm{TM}}$ and Newborn $\mathrm{Hal}^{\mathrm{TM}}$, Gaumard, Miami, Florida, USA) are used.

\section{Methods}

\section{Design}

The proposed research concerns a transmural multiprofessional simulation-based obstetric team training regarding process management of the Big 4 causes of perinatal mortality. The obstetric collaboration network consisting of ambulance staff, maternity nurses, primary care midwives, obstetric nurses, hospital midwives, residents and obstetricians will be trained.

The Ethical committee did agree that specific ethical approval is not required for this type of study in The Netherlands. Because the study does not interfere with patient care, written informed consent of the participants of the training (care givers) is not indicated. The study is planned to be implemented in a sub-region of the

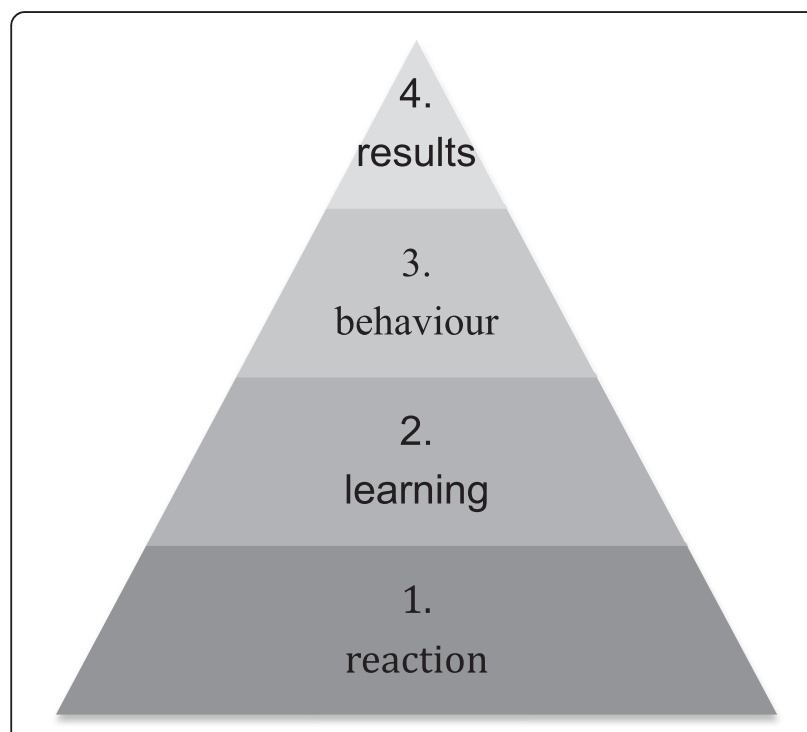

Figure 2 Kirkpatrick's model for the evaluation of training.
Netherlands (Zuidoost-Brabant) consisting of over one million inhabitants. In this area, around 120 independent midwives are providing primary care. Parallel to this project, in the same region the Regional Consortium Obstetrics Brabant has been founded. This consortium is an association of a perinatology centre (tertiary care: Máxima Medical Centre, Veldhoven), adjacent hospitals (secondary care: Jeroen Bosch hospital Den Bosch, Catharina hospital Eindhoven, Bernhoven hospital Uden, Elkerliek hospital Helmond, St Anna hospital Geldrop) and surrounding primary care midwives. Each hospital with its referring midwifery practices (regional Obstetric Cooperative) is considered to be a separate study group. A stepped wedge trial design will be employed. A stepped wedge trial is a cluster-randomised trial in which all study groups (clusters) receive the intervention by a sequential roll out of the trainings over a number of time periods. Computerised randomisation will define the sequence of the study groups. This design was chosen primarily for logistical reasons and because of the fact that all study groups will eventually receive the team training. Recent literature shows that the stepped wedge trial design has several advantages over a randomised trial, and can offer a number of opportunities. All clusters start in the control condition. The clusters will switch to the intervention at consecutive time points, where the time of the switch is randomised for every cluster. Eventually, all clusters will receive the intervention (Figure 3 ). The stepped wedge design is useful when the intervention is thought to have a beneficial effect. With a classic cluster trial, randomisation would withdraw the intervention from a part of the study groups. In addition, there are other advantages of the stepped wedge design. First, the clusters act as their own controls because they receive both the control and intervention conditions. Therefore, the intervention effect can be estimated from both between- and within-cluster comparisons. This results in more statistical power and smaller required sample sizes than in a parallel group design. The stepped wedge design is also useful where phased implementation is preferable because of logistical, practical or financial constraints [37-39].

\section{Focus groups}

Prior to the intervention, focus group interviews were performed. This resulted in insight in topics relevant to patients and care providers, concerning adequate communication and process management. The input of the focus group interviews was used for development of questionnaires for patients and care providers. The focus groups were organised separately in the following categories:

- The pregnant women and women who recently gave birth. These focus group interviews were used to 


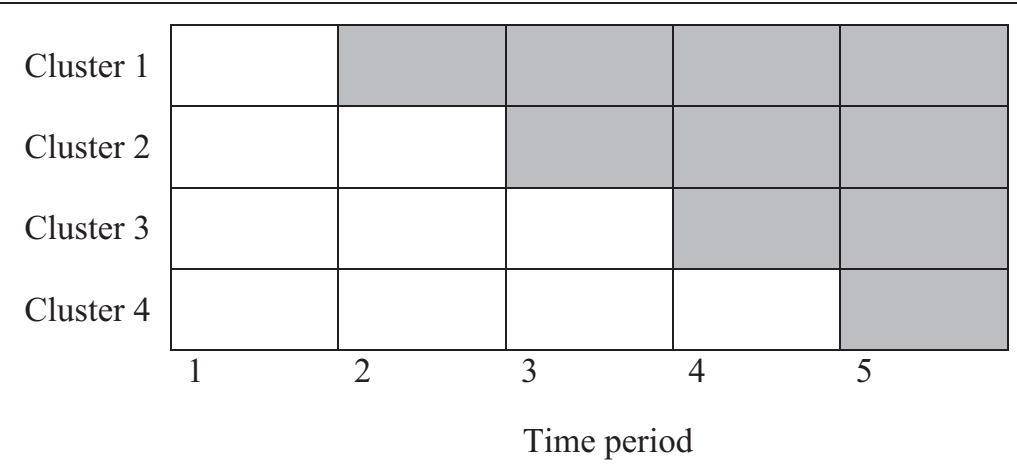

Figure 3 Stepped wedge design with 4 clusters. The grey shading indicates the start of the training according the specific cluster.

explore what is important to women regarding care during pregnancy and delivery. Based on these focus groups, the Pregnancy and Childbirth Questionnaire (PCQ), to measure quality of care as perceived by women who recently gave birth, has recently been developed and validated [28]. The PCQ will be used for an assessment of all women who recently gave birth before and after the training, concerning the entire Consortium of Brabant.

- The primary care (independent) midwife. The midwives were interviewed to evaluate most common problems in communication. This implies referral of patients to secondary/tertiary care but also aspects of communication when a client is referred back to primary care (during pregnancy/after delivery). The most relevant items were used to construct a questionnaire that will be sent out to all independent midwives for an assessment before and after the training.

- The 'maternity nurse'. This care provider was interviewed in the focus group together with the primary care midwife. The maternity nurse assists the community midwife during a home delivery. Besides that, after the delivery, she provides care to mother and child at home for about five until eight days. The communication between this nurse, the primary midwife and the patient is very important.

- Secondary care (hospital) midwife. This is an important target group because these midwives are often the first person to contact in case of referral from primary to secondary/tertiary care. Moreover, she is (together with the resident) the first person to contact the obstetrician to inform about the patient.

- The obstetrician and obstetric resident. In case of referral these medical doctors are the finals responsible for the follow-up of pregnancy/delivery. This group was interviewed to evaluate which aspects are crucial in the communication during medical handovers.

\section{Recruitment and intervention}

All obstetric care providers being part of the Consortium Brabant were invited for participating in the study. The Consortium Brabant consists of six hospitals with in total 60 obstetricians. The surrounding primary care consists of approximately 120 primary care midwives organised in about 45 independent midwifery practices. One hospital, St Anna hospital Geldrop with lowest annual delivery rate of around 1.000, decided not to join the team trainings because of logistic reasons. The region of the Máxima Medical Centre was used for a pilot study, leaving four study groups with annual around 9,000 deliveries for this study project. Every hospital with its regional Obstetric Cooperation accounts for one study group. Within the study group, training teams will be formed consisting of ambulance staff (two per team), maternity nurses (one or two per team), primary care midwives (two to five per team), obstetric nurses (two per team), secondary care midwives (one or two per team), residents (one to three per team) and obstetricians (one to three per team), representing the entire obstetric collaborative network with a total of 12-18 care providers per team. There will be two instructors/facilitators per training: one medical instructor (obstetrician) and one communication expert. An expert panel, consisting of representatives of all obstetric care levels, designed obstetric scenarios for the team training, taking into account the topics that have resulted from the focus groups. Training will focus on process management of Big 4 disorders. The focus will mainly be on non-technical skills such as CRM, communication tools and using SBAR, and less on medical technical skills. The team training will take place at the medical education and simulation centre in Eindhoven, the Netherlands (Medsim) [40]. The medical simulation centre pursues a safe learning environment for trainees.

The following four scenarios will be trained:

1. Unexpected home delivery of fetus in breech presentation

2. Extreme preterm delivery starting at home 
3. Home delivery with fetal distress and unexpected SGA

4. Unexpected resuscitation of newborn with unexpected congenital heart abnormality at home.

The scenarios are based on national and international guidelines [41-52]. Prior to the training, teams will receive an explanation concerning the equipment and environment. Each trainee will participate actively in at least one scenario and often more. Each scenario will start with an introductory briefing video. Thereafter, the team moves to the simulation room where they manage the simulated patient. State of the art high fidelity patient simulators will be used (Noelle ${ }^{\mathrm{rx}}$ and Newborn $\mathrm{Hal}^{\mathrm{m}}$, Gaumard, Miami, Florida) and patient actresses. All scenarios will be videotaped (using B-Line Medical ${ }^{\circ}$ software, Washington, DC). After each scenario a debriefing with reviewing the video recordings will be provided. The instructors will provide feedback on teamwork and skills (medical technical and non-technical) using video recordings. Learning goals based on CRM will be evaluated during the debriefing, such as: attention situational awareness, self-awareness, leadership, assertiveness, decision-making, flexibility, adaptability, and communication tools. There will be a focus on standardised communication and handovers based on the SBAR system (Situation, Background, Assessment, Recommendation).

The nine elements of DB will, if achievable, be applicated to the training by:

1) A syllabus concerning communication tools, CRM and medical knowledge about Big 4 disorders has been written and will be handed out prior to the training. To stimulate the motivation and concentration of the trainee a multiple choice exam prior to the training will be performed.

2) Learning objects:

a. prior to the training, all trainees will be asked to define an individual learning goal

b. learning goals will be defined per specific scenario and will be evaluated during the debriefing

c. take home messages will be hand over to the teams at the end of the training. The teams will work on implementing learning goals in their Obstetric Cooperation.

3) This training will not sufficiently be able to focus on an (individual) appropriate level of difficulty. In general, the scenarios have an increasing difficult level.

4) This training is a one-time training making focused and repetitive practice not achievable. However, to achieve repetitive awareness and use of communication tools based on CRM and SBAR, the study groups will use pocket charts with communication tools in daily practice.
5) Rigorous, reliable measurements: the knowledge of the trainees will be assessed by a multiple-choice exam before and after the training.

6) Feedback will be provided during the debriefing. After each scenario a debriefing session will take place. The debriefing will exist of three phases: reaction of trainees, analysis of performance and take home messages. By reviewing video recordings, feedback will focus on predefined learning goals, on team performance and application of medicals skills.

7) Monitoring and error correction will be performed by reviewing videotaped performance during the debriefing.

8) Evaluation and performance that may reach a master standard: this is not achievable, since there is no definition of what the master standard would be

9) Advancement to the next task: this is not realistic with a one-day training.

After the training, all trainees will fill in an evaluation form about their experiences concerning the training in which they will score (0-5) for 36 different items.

\section{In situ simulation}

Four months after the intervention, the effect of training on team performance will be measured by so-called unannounced (as far as possible) in situ simulations, during which care providers are assessed on their teamwork within their own working environment. The in situ simulation will consist of one or two scenarios which will be managed by a team consisting of primary and secondary care providers, located at a delivery room in the hospital. The in situ simulation will be videotaped and analysed by independent experts.

\section{Hypothesis}

Multiprofessional simulation-based obstetric team training, using CRM and elements of DP, will improve perinatal outcome, team performance, quality of care as perceived by patients and collaboration of care providers.

Questions to be answered:

1. Does multiprofessional simulation-based obstetric team training improve perinatal outcome?

2. Does multiprofessional simulation-based obstetric team training improve team performance as assessed by an unannounced in situ simulation?

3. Does multiprofessional simulation-based obstetric team training improve quality of care as perceived by patients?

4. Does multiprofessional simulation-based obstetric team training improve collaboration of care providers?

\section{Outcome measures}

Primary outcome will be a composite adverse perinatal outcome as defined by perinatal mortality and/or NICU 
admission. Data on the primary outcome will be obtained from the Netherlands Perinatal Registry (PRN).

Secondary outcomes will be:

1. 1.Team performance. For measuring team performance, an independent panel of experts will evaluate the videotaped team training sessions and calculate the Clinical Teamwork Scale (CTS) [53].

2. Quality of care as perceived by patients. This will be measured before and after the training by using a questionnaire consisting of the validated PCQ and some additional questions regarding pregnancy, delivery and the first postpartum week [28].

3. Care providers' satisfaction with teamwork and collaboration between and within the different levels of care. This will be measured before and after the training using a questionnaire which is partly based on the validated Doctors' Opinions on Collaboration (DOC) questionnaire for general practitioners and medical specialists and adjusted to the obstetric care field [54].

4. Incidence of:

a. Big 4 disorders defined as [18]:

- Small for gestational age, defined as a birth weight below the $10^{\text {th }}$ percentile

- Preterm delivery before 37 weeks

- Congenital anomalies

- Five minute Apgar score below 7

b. number of Big 4 pregnancies starting delivery in primary care

c. perinatal mortality

d. fetal mortality rate

e. neonatal mortality rate

f. NICU admission

g. admission to neonatology unit (non-NICU)

h. caesarean section

i. ventouse or forceps delivery

j. episiotomy

k. hemorrhage postpartum (>1000 $\mathrm{ml}$ of blood loss)

1. third or fourth degree perineal trauma

\section{Sample size calculation}

In 2010 perinatal mortality rate was $0.9 \%$ and the NICU admission rate $2.3 \%$. To avoid double telling, a composite rate of mortality and NICU admission will be around $3 \%$. [5]. The sample size for the study was calculated by using the formula as proposed by Woertman and De Hoop [38]. This formula calculates the design effect required on top of the sample size calculation for a standard randomised clinical trial (RCT). To show a reduction in perinatal mortality and NICU admission rate from $3 \%$ to $1.65 \%$, with an alpha of 0.05 and a power of $80 \%$, a total of 4,000 deliveries would be needed for a simple RCT design. The design effect was calculated assuming an intracluster correlation (ICC) of 0.05 , a cluster size of 1,800 deliveries per year, and four clusters or study groups. Taking into account the design effect, we need 565 deliveries per measurement period per cluster. To achieve this number we need 16 weeks for each period, adding up to a total study period of 82 weeks including a 16-week control period before the first training. A mixed effects model will be used to model the data and test the hypothesis of no effect from team training to accommodate cluster effects and time effects. Statistical significance will be accepted at a two-sided $\mathrm{p}$-value $<0.05$. In the study region 9,000 deliveries occur per year, with a minimum of around 1,806 deliveries per year per study group (cluster) and a maximum of around 3,500.

\section{Discussion}

As far as we know now, transmural multiprofessional simulation-based obstetric team training, using CRM and elements of DP, integrating the entire obstetric collaborative network, has never been studied before. We hypothesise that this obstetric team training improves perinatal outcome, team performance, quality of care as perceived by patients, and collaboration between care providers. The current project fits well within one of the main goals of the Dutch government to set up research that can prevent avoidable perinatal mortality and morbidity. Management of obstetric scenarios, based on the Big 4 causes of perinatal mortality, will be practiced in a medical simulation centre by teams with representatives of the obstetric collaborative network. The innovative aspect of the current project is the focus on non-technical skills (CRM, SBAR) rather than technical skills with the application of the elements of DP and defining learning goals based on CRM and the fact that different care providers will be trained together in one integrative cooperating team. Because team training and communication training has shown to be effective in secondary obstetric care [36], there is no reason to believe that this will not work within team training with integrating care providers from primary, secondary and tertiary care. To achieve a better ranking position concerning perinatal mortality rates in Europe, it is necessary to intensify an integrative organisation of obstetric care in the Netherlands in which all different care levels will integrate, in which uniform care paths will be developed forming 'patient centered care'. This is in line with the recent letter of the Minister of Health which has been sent to the House of Parliament in which she focuses on the development of an integrative obstetric health system.

\section{Abbreviations}

CRM: Crew resource management; CTS: Clinical teamwork scale; DOC: Doctors' opinion on collaboration; DP: Deliberate practice; Medsim: Medical education and simulation centre Eindhoven; NICU: Neonatal Intensive Care Unit; OHC: Obstetric high care; PRN: National 
Dutch Perinatal Registry; SBAR: Situation, Background, Assessment, Recommendation; SBME: Simulation-Based Medical Education; SGA: Small for gestational age; SSF: Substandard factors; ZonMw: the Netherlands Organization for Health, Research and Development.

\section{Competing interests}

The authors declare that they have no competing interests.

\section{Authors' contributions}

All authors were involved in conception and design of the study. All authors participated in the design of the study during several meetings and are local investigators at the participating centers. All authors drafted the manuscript. All authors edited the manuscript and read and approved the final manuscript.

\section{Acknowledgements}

\section{Funding}

This study is funded by ZonMw, the Netherlands Organization for Health, Research and Development, project number 2009020010

\section{Author details}

'Department of Obstetrics and Gynaecology, Máxima Medical Centre, De Run 4600, P.O. Box 7777, 5500 MB Veldhoven, The Netherlands. ${ }^{2}$ MMC Academie, Máxima Medical Centre, Veldhoven, The Netherlands. ${ }^{3}$ Department of Electrical Engineering, Eindhoven University of Technology, Eindhoven, The Netherlands.

Received: 15 July 2014 Accepted: 14 August 2014 Published: 21 August 2014

\section{References}

1. Buitendijk SE, Nijhuis JG: High perinatal mortality in the Netherlands compared to the rest of Europe. Ned Tijdschr Geneeskd 2004, 148:1855-1860.

2. Mohangoo AD, Buitendijk SE, Hukkelhoven CW, Ravelli AC, van Driel GC R, Tamminga $P$, et al: Higher perinatal mortality in the Netherlands than in other European countries: the Peristat-II study. Ned Tijdschr Geneeskd 2008, 152:2718-2727.

3. Zeitlin J, Mohangoo A, Cuttini M, EURO-PERISTAT Report Writing Committee: The European Perinatal Health Report: comparing the health and care of pregnant women and newborn babies in Europe. J Epidemiol Community Health 2009, 63:681-682.

4. EURO-PERISTAT project in collaboration with SCPE, EUROCAT and EURONEOSTAT: European perinatal health report; 2008. www.europeristat.com

5. Euro-Peristat Project with SCPE and EUROCAT: European Perinatal Health Report. In The health and care of pregnant women and babies in Europe in 2010; www.europeristat.com.

6. Eurostat: The Eurostat Regional Yearbook. Publications Office of the European Union: Luxembourg; 2011.

7. The Netherlands Perinatal Registry: Trends 1999-2012. The Netherlands Perinatal Registry: Utrecht; 2013

8. Commissie verloskunde van het CVZ: Verloskundig vademecum 2003. Diemen: College voor zorgverzekeringen; 2003.

9. Franx A: Lijn der verwachting. Utrecht University: Utrecht; 2011.

10. Stuurgroep zwangerschap en geboorte: Een goed begin. Utrecht: Stuurgroep zwangerschap en geboorte; 2009.

11. PRN 2007: Perinatale Zorg in Nederland 2007. Utrecht: PRN; 2009. www.perinatreg. nl/uploads/150/116/Jaarboek_Perinatale_Zorg_2007.pdf

12. Amelink-Verburg MP, Verloove-Vanhorick SP, Hakkenberg RM, Veldhuijzen IM, Bennebroek GJ, Buitendijk SE: Evaluation of 280,000 cases in Dutch midwifery practices: a descriptive study. BJOG 2008, 115:570-578.

13. Van Eyck JPM, Offermans AC, Bolte KM, Sollie-Szarynska KWM, Bloemenkamp SG, Oei MP, Heringa FK, Lotgering JJ, Duvekot A, Schaap AHP: OHC rapportage 2008. Ned Tijdschr Geneeskd 2008, 152:2121-2125

14. de Neef T, Hukkelhoven CW, Franx A, Everhardt E: Uit de lijn der verwachting. Nederl Tijdschrift Obstet Gynaecol 2009, 122:341-342.

15. Evers AC, Brouwers HA, Hukkelhoven CW, Nikkels PG, Boon J, van Egmond-Linden A, Hillegersberg J, Snuif YS, Sterken-Hooisma S, Bruinse HW, Kwee A: Perinatal mortality and severe morbidity in low and high risk pregnancies in the Netherlands: a prospective cohort study. BMJ 2010, 341:c5639.
16. de Jonge A, van der Goes B, Ravelli A, Amelink-Verburg M, Mol B, Nijhuis J, Bennebroek Gravenhorst J, Buitendijk S: Perinatal mortality and morbidity in a nationwide cohort of 529688 low-risk planned home and hospital births. BJOG 2009, 116:1177-1184.

17. Birthplace in England Collaborative Group: Perinatal and maternal outcomes by planned place of birth for healthy women with low risk pregnancies: the Birthplace in England national prospective cohort study. BMJ 2011, 343:d7400.

18. Bonsel GJ, Birnie E, Denktas S, Poeran J, Steegers EAP: Lijnen inde Perinatale Sterfte, Signalementstudie Zwangerschap en Geboorte 2010. Rotterdam: Erasmus MC; 2010

19. Ravelli ACJ, Eskes M, Tromp M, van Huis AM, Steegers EAP, Tamminga P. Bonsel GJ: Perinatale sterfte in Nederland 2000-2006; risicofactoren en risicoselectie. Ned Tijdschr Geneeskd 2008, 152:2728-2733.

20. Tamminga P, Rijninks-van Driel G, Mohangoo A, Hukkelhoven C, Nijhuis J, Buitendijk S, Ravelli ACJ: Neonatale uitkomsten. Nederl Tijdschrift Obstet Gynaecol 2009, 122:83-87.

21. Richardus JH, Graafmans WC, Verloove-Vanhorick SP, Mackenbach JP, EuroNatal International Audit Panel; EuroNatal Working Group: Differences in perinatal mortality and suboptimal care between 10 European regions: results of an international audit. BJOG 2003, 110:97-105.

22. Stichting Perinatale Audit Nederland: A terme sterfte 2010. Perinatale audit: eerste verkenningen. Stichting Perinatale Audit Nederland: Utrecht; 2011.

23. Lledo R, Rodríguez T, Trilla A, Cararach V, Restuccia J, Asenjo M: Perceived quality of care in pregnancy. Assessment before and after delivery. Eur J Obstet Gynecol Reprod Biol 2000, 88:35-42.

24. Wildman K, Blondel B, Nijhuis J, Defoort P, Bakoula C: European indicators of health care during pregnancy, delivery and the postpartum period. Eur J Obstet Gynecol Reprod Biol 2003, 111:53-65.

25. Draycott T, Sibanda T, Laxton C, Winter C, Mahmood T, Fox R: Quality improvement demands quality measurement. BJOG 2010, 117:1571-1574.

26. Siassakos D, Bristowe K, Draycott TJ, Angouri J, Hambly H, Winter C, Crofts $J F$, Hunt LP, Fox R: Clinical efficiency in a simulated emergency and relationship to team behaviours: a multisite cross-sectional study. BJOG 2011, 118:596-607.

27. Posthumus AG, Schölmerich VL, Waelput AJ, Vos AA, De Jong-Potjer LC, Bakker R, Bonsel GJ, Groenewegen P, Steegers EA, Denktaş S: Bridging between professionals in perinatal care: towards shared care in the Netherlands. Matern Child Health J 2013, 17(10):1981-1989.

28. Truijens SEM, Pommer AM, Van Runnard Heimel PJ, Verhoeven CJM, Oei SG, Pop VJM: Development of the Pregnancy and Childbirth Questionnaire (PCQ): evaluating quality of care as perceived by women who recently gave birth. Eur J Obstet Gynecol Reprod Biol 2014, 174:35-40.

29. Draycott T, Sibanda T, Owen L, Akande V, Winter C, Reading S, Whitelaw A Does training in obstetric emergencies improve neonatal outcome? BJOG 2006, 113:177-182

30. Cook DA, Hatala R, Brydges R, Zendejas B, Szostek JH, Wang AT, Erwin PJ, Hamstra SJ: Technology-enhanced simulation for health professions education; a systematic review and meta-analysis. JAMA 2011, 306:978-988.

31. McGaghie WC, Issenberg SB, Cohen ER, Barsuk JH, Wayne DB: Does simulation-based medical education with deliberate practice yield better results than traditional clinical education? A meta-analytic comparative review of the evidence. Acad Med 2011, 86:706-711.

32. Ericsson KA: Deliberate practice and the acquisition and maintenance of expert performance in medicine and related domains. Review. Acad Med 2004, 79(10 Suppl):S70-S81.

33. Helmreich RL, Merrit AC, Wilhelm JA: The evolution of crew resource management in training in commercial aviation. Int J Aviat Psychol 1999, 9:19-32.

34. Grogan EL, Stiles RA, France DJ, Speroff T, Morris JA, Nixon B, Gaffney FA, Seddon $R$, Pinson CW: The impact of aviation-based teamwork training on the attitudes of health-care professionals. J Am Coll Surg 2004, 199:843-848.

35. Kirkpatrick D: Evaluating training programmes; the four levels. San Francisco, CA: Berrett-Kochler Publishers; 1994.

36. Fransen AF, van de Ven J, Merién AER, de Wit-Zuurendonk L, Houterman S, Mol BW, Oei SG: Effect of obstetric team training on team performance and medical technical skills: a randomised controlled trial. $\mathrm{Br} J \mathrm{Obstet}$ Gynaecol 2012, 119:1387-1393.

37. Brown CA, Lilford RJ: The stepped wedge trial design, a systematic review. BMC Med Res Methodol 2006, 8:6-54 
38. Woertman W, de Hoop E, Moerbeek M, Zuidema SU, Gerritsen DL, Teerenstra S: Stepped wedge designs could reduce the required sample size in cluster randomized trials. J Clin Epidemiol 2013, 66(7):752-758.

39. Mdege ND, Man MS, Taylor Nee Brown CA, Torgerson DJ: Systematic review of stepped wedge cluster randomized trials shows that design is particularly used to evaluate interventions during routine implementation. J Clin Epidemiol 2011, 64(9):936-948.

40. Medical Education and Simulation Centre (Medsim): the Netherlands: Eindhoven. www.medsim.nl.

41. Dutch Society of Obstetrics and Gynaecology: Multidisciplinary guideline of preterm birth. NVOG: Utrecht; 2012. www.nvog.nl.

42. Dutch Society of Obstetrics and Gynaecology: Guideline prevention of recurrence of preterm birth. NVOG: Utrecht; 2007. www.nvog.nl.

43. Dutch Society of Obstetrics and Gynaecology: Guideline calculation of gestational age. NVOG: Utrecht; 2011. www.nvog.nl.

44. Dutch Society of Obstetrics and Gynaecology: Multidisciplinary guideline of extreme preterm birth. NVOG: Utrecht; 2010. www.nvog.nl.

45. Royal College of Obstetricians and Gynaecologists (RCOG): The Investigation and Management of the Small-for-Gestational-Age Fetus. In RCOG green Guidline NO 31. London: RCOG; 2013.

46. Dutch Society of Obstetrics and Gynaecology: Small-for-Gestational-Age Fetus. NVOG: Utrecht; 2008.

47. Royal College of Obstetricians and Gynaecologists (RCOG): Electrical fetal monitoring. In National Evidence-based Clinical Guideline. London: RCOG Press; 2001.

48. Health, National Collaborating Centre for Women's and Children's: Intrapartum Care: care of healthy women and their babies during childbirth. In NICE Clinical guideline 55. Londen: RCOG Press; 2007.

49. Nederlandse Reanimatie Raad/Belgische reanimatieraad: Resuscitation of newborns; guidelines resuscitation in the Netherlands. Nederlandse Reanimatie Raad: Uden; 2010. www.reanimatieraad.nl.

50. Nolan JP, Soar J, Zideman DA, Biarent D, Bossaert LL, Deakin C, Koster RW, Wyllie J, Böttiger B: ERC Guidelines Writing Group. European Resuscitation Council Guidelines for Resuscitation 2010 Section 1. Executive summary. Resuscitation 2010, 81(10):1219-1276.

51. Dutch Society of Obstetrics and Gynaecology: Guideline unexpected findings with 18-20 week scan. NVOG: Utrecht; 2008.

52. Dutch Society of Obstetrics and Gynaecology: Guideline late termination of pregnancy. NVOG: Utrecht; 2007.

53. Guise JM, Deering SH, Kanki BG, Osterweil P, Li H, Mori M, Lowe NK: Validation of a tool to measure and promote clinical teamwork. Simul Healthc 2008 , 3:217-223.

54. Berendsen AJ, Benneker WH, Groenier KH, Schuling J, Grol RP, Meyboom-de JB: DOC questionnaire: measuring how GPs and medical specialists rate collaboration. Int J Health Care Qual Assur 2010, 23:516-526.

doi:10.1186/1472-6920-14-175

Cite this article as: Banga et al.: The impact of transmural

multiprofessional simulation-based obstetric team training on perinatal outcome and quality of care in the Netherlands. BMC Medical Education 2014 14:175

\section{Submit your next manuscript to BioMed Central and take full advantage of:}

- Convenient online submission

- Thorough peer review

- No space constraints or color figure charges

- Immediate publication on acceptance

- Inclusion in PubMed, CAS, Scopus and Google Scholar

- Research which is freely available for redistribution 